Article

\title{
Threshold Value Determination Using Machine Learning Algorithms for Ba Interference with Eu in Coal and Coal Combustion Products by ICP-MS
}

\author{
$\mathrm{Na} \mathrm{Xu}{ }^{1, *(D)}$ and Qing $\mathrm{Li}^{2}$ \\ 1 College of Geoscience and Survey Engineering, China University of Mining and Technology, \\ Beijing 100083, China \\ 2 Department of Computing, Hong Kong Polytechnic University, Hung Hom, Kowloon, HKSAR, \\ Hong Kong, China; qing-prof.li@polyu.edu.hk \\ * Correspondence: xuna1011@gmail.com; Tel.: +86-10-6233-9307
}

Received: 15 March 2019; Accepted: 24 April 2019; Published: 29 April 2019

\begin{abstract}
Ba-based ion interference with Eu in coal and coal combustion products during quadrupole-based inductively coupled plasma mass spectrometry procedures is problematic. Thus, this paper proposes machine-learning-based prediction models for determination of the threshold value of $\mathrm{Ba}$ interference with $\mathrm{Eu}$, which can be used to predict such interference in coal. The models are trained for $\mathrm{Eu}, \mathrm{Ba}, \mathrm{Ba} / \mathrm{Eu}$, and $\mathrm{Ba}$ interference with Eu. Under different user-defined parameters, different prediction models based on the corresponding model tree can be applied to Ba interference with Eu. We experimentally show the effectiveness of these different prediction models and find that, when the $\mathrm{Ba} / \mathrm{Eu}$ value is less than 2950, the Ba-Eu interference prediction model is $y=-0.18419411+0.00050737 \times x, 0<x<2950$. Further, when the $\mathrm{Ba} / \mathrm{Eu}$ value is between 2950 and 189,523, the Ba-Eu interference prediction model of $y=0.293982186+0.00000181729975 \times x, 2950<x<189,523$ yields the best result. Based on the optimal model, a threshold value of 363 is proposed; i.e., when the Ba/Eu value is less than 363, Ba interference with Eu can be neglected during Eu data interpretation. Comparison of this threshold value with a value proposed in earlier works reveals that the proposed prediction model better determines the threshold value for Ba interference with $\mathrm{Eu}$.
\end{abstract}

Keywords: europium; ICP-Q-MS; polyatomic ion inference; coal; machine learning; regression

\section{Introduction}

Rare earth elements and yttrium (REY, or REE if Y is excluded) in coal and coal combustion products (CCPs), e.g., fly and bottom ash, have attracted much attention in recent years, not only because of the high international demand for these technologically important elements, but also because of the restrictions on export from China [1,2]. Seredin and Dai [3] and Dai et al. [4] have shown that coal has high potential as a REY source, given that the average concentration of REY oxides (REO) in world coal ash is $485 \mu \mathrm{g} / \mathrm{g}$, which is half the cut-off grade of REO in CCPs (1000 $\mu \mathrm{g} / \mathrm{g})$. In some cases, CCPs contain $>1000 \mu \mathrm{g} / \mathrm{g}$ REO; thus, they could constitute an economically viable source for REY extraction. Previous investigations have shown that some coals from China [5-7], Russia [3,8], and the USA contain high concentrations of REY [9-11], comparable to or even higher than those of conventional REY deposits [3]. Other studies concerning REY resources [12,13], modes of REY occurrence in coal and CCPs [14,15], and extraction technology [16] have also suggested the great potential of coal as REY source.

The REY (including Eu) concentration in coal and CCPs can be determined via several methods, including X-ray fluorescence spectrometry (XRF) $[17,18]$, instrumental neutron activation analysis 
(INAA) [19-21], laser-ablation inductively-coupled plasma mass spectroscopy (La-ICP-MS) [22], sector-field inductively-coupled plasma mass spectroscopy ICP-MS [23], laser-induced break-down spectrometry [24-26], and quadrupole-based ICP-MS (ICP-Q-MS) [4,27]. Among these techniques, ICP-Q-MS has mostly been used for determination of REY concentrations in coal and CCPs. This is because of this method's ability to rapidly, precisely, and accurately measure REY content at very low detection limits in liquid and solid samples, with relatively simple spectra and a wide linearity range [14,27-29]. However, in some cases, Eu concentrations in coal and CCPs cannot be accurately measured by the ICP-Q-MS. This difficulty is attributed to overlapping ion interference (such as those from $\mathrm{M}^{+}, \mathrm{MO}^{+}$, and/or $\mathrm{MOH}^{+}$ions) with Eu, which affects interpretation of the ICP-Q-MS spectra [30-35]. Because Ba concentrations in coal and CCPs are generally much higher than those of $\mathrm{Eu}[4,36]$, the most significant types of interference encountered for $\mathrm{Eu}$ in coal and CCPs are due to ${ }^{135} \mathrm{Ba}^{16} \mathrm{O},{ }^{134} \mathrm{Ba}^{16} \mathrm{OH},{ }^{137} \mathrm{Ba}^{16} \mathrm{O}$, and/or ${ }^{136} \mathrm{Ba}^{16} \mathrm{OH}$ interfering with ${ }^{151} \mathrm{Eu}$ and/or ${ }^{153} \mathrm{Eu}$. For example, the ratio of Ba vs. Eu for world coals is as high as $~ 882$ (with an average concentration of $150 \mu \mathrm{g} / \mathrm{g}$ $\mathrm{Ba}$ and $0.47 \mu \mathrm{g} / \mathrm{g} \mathrm{Eu}$ ) [36]. Therefore, as noted by Dai et al. [4], Eu content values in coal and CCPs determined via ICP-Q-MS should be treated with great caution.

Recently, Yan et al. [27] described a reliable analytical method to avoid Ba-based ion interference with Eu in coal, CCPs, and sedimentary rocks during ICP-Q-MS procedures, which was based on AG50W-X8 cation exchangeable chromatography. Yan et al. [27] provided an estimated Ba/Eu threshold value of 1000 and demonstrated that the determined Eu concentration should not be used if the $\mathrm{Ba} / \mathrm{Eu}$ ratio exceeds this threshold value and if no effective action has been taken to avoid Ba interference with $\mathrm{Eu}$. However, the $\mathrm{Ba} / \mathrm{Eu}$ threshold value estimated by Yan et al. [27] is an approximation. In a different context, Loges et al. [35] also suggested an experience-based threshold value, i.e., $\mathrm{Ba} / \mathrm{Eu}>1000$, to exclude interference of Ba with Eu in ICP-Q-MS analyses of Eu content values; however, this is not an accurate estimation either. Determination of an accurate $\mathrm{Ba} / \mathrm{Eu}$ threshold value is important not only to determine if coal can potentially be used as a REY source, but also to deduce the geological setting of coal formation using $\mathrm{Eu}$ as a reliable indicator.

In this paper, we propose a threshold value at which Ba interference with Eu has a meaningful effect on ICP-Q-MS results, which is determined via prediction models created using machine learning algorithms. All Eu and Ba training data employed in this study are from Yan et al. [27]. Yan's work [27] has significantly diminished the inference of ${ }^{137} \mathrm{Ba}^{16} \mathrm{O},{ }^{136} \mathrm{Ba}^{17} \mathrm{O},{ }^{135} \mathrm{Ba}^{18} \mathrm{O}$, and ${ }^{134} \mathrm{Ba}^{18} \mathrm{OH}$ on ${ }^{153} \mathrm{Eu}$ in related samples. They used a Bio-Rad AG50W-x8 cation exchange resin to effectively separate Ba from digested solutions of related coal and CCP samples. The results as presented by Yan et al. [27] showed that the determination of Ba and Eu in the National Institute of Standards Technology (NIST) standard references of coal and fly ash samples using this method is quite reliable. Also, Yan et al. [27] showed that the detection limits for Ba and Eu are very low, $0.030 \mu \mathrm{g} / \mathrm{L}$ and $0.006 \mu \mathrm{g} / \mathrm{L}$, respectively, and the determination coefficient of their calibration curves is $>0.9999$. Unlike other ICP-Q-MS data which were obtained based on non-separation between $\mathrm{Ba}$ and $\mathrm{Eu}$ in solutions digested from solid samples (e.g., coal samples in the U.S. Geological Survey's WoCQI database, Palmer et al. [37], and in other numerous published papers, for example but not limited to references [38-46]), the data by Yan et al. [27] provided a good opportunity for determining the threshold value using machine learning algorithms for $\mathrm{Ba}$ interference with $\mathrm{Eu}$ in coal and coal combustion products by ICP-Q-MS. However, there have been some studies to assess the interference of ${ }^{135} \mathrm{Ba}^{16} \mathrm{O},{ }^{134} \mathrm{Ba}^{16} \mathrm{OH},{ }^{137} \mathrm{Ba}^{16} \mathrm{O}$, and/or ${ }^{136} \mathrm{Ba}^{16} \mathrm{OH}$ on ${ }^{151} \mathrm{Eu}$ and/or ${ }^{153} \mathrm{Eu}$, e.g., determining the yield of Ba-based oxide and hydroxide ions using a single-element solution of $\mathrm{Ba}$ (e.g., $500 \mathrm{ng} / \mathrm{mL} \mathrm{Ba}$ in $\mathrm{BaCl}_{2}$ solution) and compare the yield of potential interfering irons (e.g., $\left.{ }^{135} \mathrm{Ba}^{16} \mathrm{O}\right)$ with the $\mathrm{Eu}$ ions $\left({ }^{151} \mathrm{Eu}\right)$ that has the same mass number in a single-element solution of Eu [47-49]. A study by Dulski [48] shows that that $1000 \mathrm{ng} / \mathrm{g}$ Ba could cause $0.22 \mathrm{ng} / \mathrm{g} \mathrm{Eu}$. Another approach to evaluating the degree of the interference is to analyze the correlation relation between $\mathrm{Ba}$ and $\mathrm{Eu}$ in the related samples, i.e., a linear Ba-Eu correlation indicating distinct interference of Ba with Eu [50-56]. 
Classification and regression are two typical algorithms in machine learning [57], with the difference between them being that their target variables are discrete and continuous, respectively [58]. Here, we employ a model tree [57] based on linear regression and a regression tree to construct prediction models for this interference. Based on analysis of $\mathrm{Ba}, \mathrm{Eu}$, and $\mathrm{Ba} / \mathrm{Eu}$, the target variables for Ba interference with $\mathrm{Eu}$ are found to be continuous. Thus, we adopt the regression method for prediction of Ba interference with Eu. Empirically, we find that it is difficult to precisely construct a global prediction model using linear regression because of the element data complexity. To overcome this problem, the models are adjusted to split the element data according to many partitions. In the case of the regression tree, classification and regression tree (CART) algorithms [59] are then applied.

\section{Proposed Machine Learning Models for Prediction of Ba Interference with Eu}

In this study, machine learning algorithms were used to develop models of Ba interference with $\mathrm{Eu}$ in coal. Note that, when a pair of element datasets (e.g., $\left(x_{1}^{\mathrm{Ba}}, \ldots, x_{i}^{\mathrm{Ba}}\right)$ and $\left(x_{1}^{\mathrm{Eu}}, \ldots, x_{i}^{\mathrm{Eu}}\right)$ for Ba and $\mathrm{Eu}$, respectively) is established, the interference between them is difficult to determine. Effective $\mathrm{Ba}-\mathrm{Eu}$ interference prediction depends on various factors including the element concentration, element interference, and samples.

Here, three machine learning models were used to predict Ba interference with Eu, incorporating linear regression, regression trees, and model trees. The problem of threshold value identification can be represented as the problem of constructing a prediction model between a Ba interference with $\mathrm{Eu}$ dataset $\left(y_{1 \text { prediction }}^{\mathrm{Ba} / \mathrm{Eu}}, \ldots, y_{i \text { prediction }}^{\mathrm{Ba} / \mathrm{Eu}}\right)$ and $\mathrm{Ba}, \mathrm{Eu}$, and $\mathrm{Ba} / \mathrm{Eu}$ ratio datasets $\left(x_{1}^{\mathrm{Ba}}, \ldots, x_{i}^{\mathrm{Ba}}\right),\left(x_{1}^{\mathrm{Eu}}, \ldots, x_{i}^{\mathrm{Eu}}\right)$ and $\left(x_{1}^{\mathrm{Ba}} / x_{1}^{\mathrm{Eu}}, \ldots, x_{i}^{\mathrm{Ba}} / x_{i}^{\mathrm{Eu}}\right)$ respectively.

\subsection{Linear Regression Model for Prediction of Ba Interference with Eu}

\subsubsection{Linear Regression Model}

The $\left(x_{1}^{\mathrm{Ba}}, \ldots, x_{i}^{\mathrm{Ba}}\right)$ and $\left(x_{1}^{\mathrm{Eu}}, \ldots, x_{i}^{\mathrm{Eu}}\right)$ datasets used in this study were based on a number of coal and ash samples. Furthermore, based on experiments by Yan et al. [27], we calculated $\left(x_{1}^{\mathrm{Ba}} / x_{1}^{\mathrm{Eu}}, \ldots, x_{i}^{\mathrm{Ba}} / x_{i}^{\mathrm{Eu}}\right)$. The linear regression prediction model for Ba-Eu interference is:

$$
y_{i \text { prediction }}^{\mathrm{Ba} / \mathrm{Eu}}=\left(x_{i}^{\mathrm{Ba}} / x_{i}^{\mathrm{Eu}}\right)^{T} w_{\text {iprediction }}
$$

Specifically, the target variable of Ba-Eu interference $y_{i \text { prediction }}^{\mathrm{Ba}}$ is related to the different element concentrations, i.e., $\left(x_{1}^{\mathrm{Ba}}, \ldots, x_{i}^{\mathrm{Ba}}\right),\left(x_{1}^{\mathrm{Eu}}, \ldots, x_{i}^{\mathrm{Eu}}\right)$ and $\left(x_{1}^{\mathrm{Ba}} / x_{1}^{\mathrm{Eu}}, \ldots, x_{i}^{\mathrm{Ba}} / x_{i}^{\mathrm{Eu}}\right)$. Linear regression for Ba-Eu interference predicts target interference values. In the model given in Equation (1), the vector $w_{i p r e d i c t i o n}$ is the regression weight. Regression is used to find $w_{\text {iprediction }}$ and hence, the Ba-Eu interference values are predicted.

\subsubsection{Ba-Eu Interference Prediction Error}

The error is defined as the difference between the actual $\mathrm{Ba}$ interference with $\mathrm{Eu} y_{i}^{\mathrm{Ba} / \mathrm{Eu}}$ and $y_{\text {iprediction; }}^{\mathrm{Ba} / \mathrm{Eu} \text { i.e., }}$

$$
\sum_{i=1}^{m}\left(\left(x_{i}^{\mathrm{Ba}} / x_{i}^{\mathrm{Eu}}\right)^{T} w_{i \text { prediction }}-y_{i}^{\mathrm{Ba} / \mathrm{Eu}}\right)^{2}
$$

\subsubsection{Machine Learning Process for Ba-Eu Interference Prediction}

Training: First, all input concentrations of $\mathrm{Ba}, \mathrm{Eu}$, and the $\mathrm{Ba} / \mathrm{Eu}$ ratio values (i.e., $\left(x_{1}^{\mathrm{Ba}}, \ldots, x_{i}^{\mathrm{Ba}}\right)$, $\left(x_{1}^{\mathrm{Eu}}, \ldots, x_{i}^{\mathrm{Eu}}\right)$ and $\left.\left(x_{1}^{\mathrm{Ba}} / x_{1}^{\mathrm{Eu}}, \ldots, x_{i}^{\mathrm{Ba}} / x_{i}^{\mathrm{Eu}}\right)\right)$, and the interference values of Ba with $\mathrm{Eu}\left(y_{1}^{\mathrm{Ba} / \mathrm{Eu}}, \ldots, y_{i}^{\mathrm{Ba} / \mathrm{Eu}}\right)$ 
are entered. All the input training element data values are prepared and converted into matrices. The interference error of the above elements can also be expressed in matrix notation, as:

$$
w_{\text {iprediction }}=\left(\left(x_{i}^{\mathrm{Ba}} / x_{i}^{\mathrm{Eu}}\right)^{T}\left(x_{i}^{\mathrm{Ba}} / x_{i}^{\mathrm{Eu}}\right)\right)^{-1}\left(x_{i}^{\mathrm{Ba}} / x_{i}^{\mathrm{Eu}}\right)^{T} y_{i}^{\mathrm{Ba} / \mathrm{Eu}}
$$

This equation is solved using the ordinary least squares method. Hence, $w_{\text {iprediction }}$ is predicted according to the best estimate based on the training element data values.

Prediction: Based on the training process described above, the prediction for $\mathrm{Ba}-\mathrm{Eu}$ interference can be estimated from the formula:

$$
y_{\text {iprediction }}^{\mathrm{Ba} / \mathrm{Eu}}=\left(x_{i}^{\mathrm{Ba}} / x_{i}^{\mathrm{Eu}}\right)^{T} w_{\text {iprediction }} .
$$

\subsection{Regression Tree Model for Prediction of Ba Interference with Eu}

Regression Tree Model

The elements have many features, i.e., $x_{i}^{\mathrm{Ba}}, x_{i}^{\mathrm{Eu}}, x_{i}^{\mathrm{Ba}} / x_{i}^{\mathrm{Eu}}$ and $y_{i}^{\mathrm{Ba} / \mathrm{Eu}}$, and samples $C_{i}^{\mathrm{Ba}}$ and $C_{i}^{\mathrm{Eu}}$. The linear regression model cannot achieve good fitting of $\left(x_{1}^{\mathrm{Ba}}, \ldots, x_{i}^{\mathrm{Ba}}\right),\left(x_{1}^{\mathrm{Eu}}, \ldots, x_{i}^{\mathrm{Eu}}\right)$ and $\left(x_{1}^{\mathrm{Ba}} / x_{1}^{\mathrm{Eu}}, \ldots, x_{i}^{\mathrm{Ba}} / x_{i}^{\mathrm{Eu}}\right)$ with $\left(y_{1 \text { prediction }}^{\mathrm{Ba} / \mathrm{Eu}}, y_{\text {iprediction }}^{\mathrm{Ba} / \mathrm{Eu}}\right)$, as shown in Figure 1; thus, a nonlinear model emerges. The nonlinear model partitions the element concentrations and Ba-Eu interference. Every partition can be constructed with linear regression models. Note that in Figure 1, the $x$-axis is the ratio of Ba vs. Eu in digested solutions derived from solid samples before Ba is separated from Eu in the solutions; and $y$-axis is the Eu concentration contributed from Ba ions.

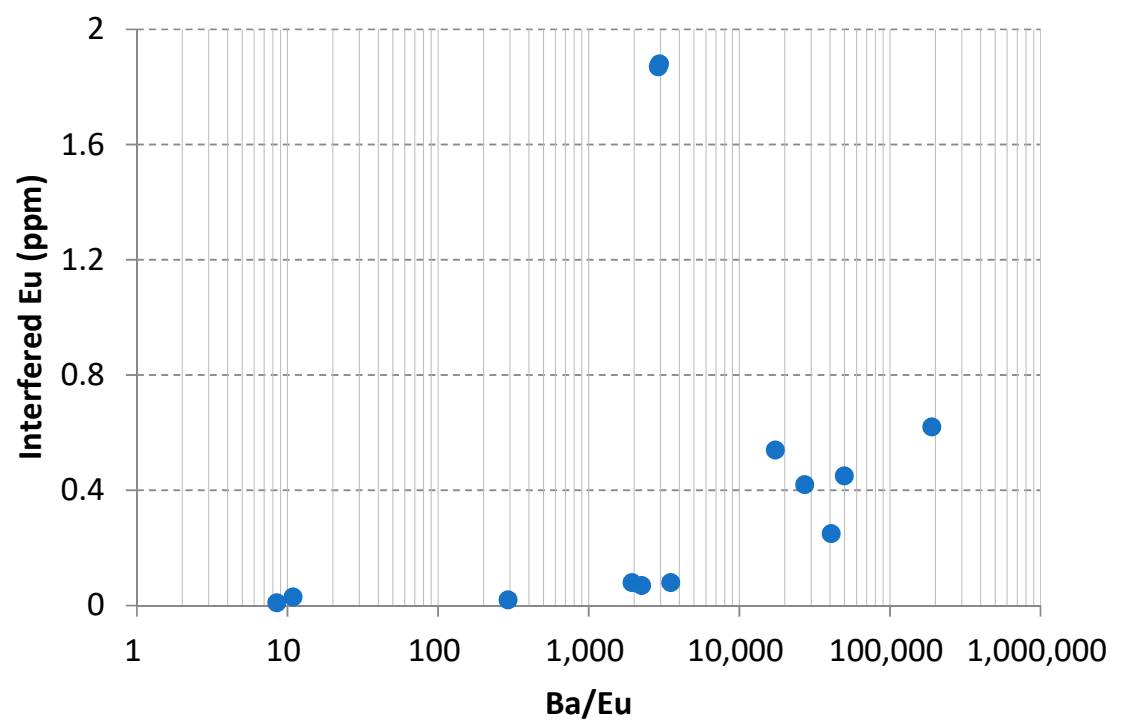

Figure 1. Training data (from Yan et al. [27]).

The steps of the CART algorithm for constructing the regression tree model for prediction of $\mathrm{Ba}$ interference with $\mathrm{Eu}$ are as follows. The extracted feature is $\mathrm{Ba} / \mathrm{Eu}$, i.e., $\left(x_{1}^{\mathrm{Ba}} / x_{1}^{\mathrm{Eu}}\right), \ldots,\left(x_{i}^{\mathrm{Ba}} / x_{i}^{\mathrm{Eu}}\right)$. The extracted feature value is the interference of Ba with $\mathrm{Eu}$, i.e., $y_{1}^{\mathrm{Ba} / \mathrm{Eu}}, \ldots, y_{i}^{\mathrm{Ba} / \mathrm{Eu}}$. For every $\left(x_{1}^{\mathrm{Ba}} / x_{1}^{\mathrm{Eu}}\right), \ldots,\left(x_{i}^{\mathrm{Ba}} / x_{i}^{\mathrm{Eu}}\right)$, binary splits are executed to yield two parts $\left(x_{1}^{\mathrm{Ba}} / x_{1}^{\mathrm{Eu}}\right), \ldots,\left(x_{j}^{\mathrm{Ba}} / x_{j}^{\mathrm{Eu}}\right)<s,\left(x_{j}^{\mathrm{Ba}} / x_{j}^{\mathrm{Eu}}\right), \ldots,\left(x_{i}^{\mathrm{Ba}} / x_{i}^{\mathrm{Eu}}\right)>s$. Then, for every feature in the two different 
parts, $y_{1 \text { prediction }}^{\mathrm{Ba} / \mathrm{Eu}}, y_{\text {iprediction }}^{\mathrm{Ba} / \mathrm{Eu}}$ is calculated based on Equation (5). The process surveys every feature and value to find the best split that minimizes the error:

$$
\begin{aligned}
& \min \left\{\min \sum_{x_{i}^{B a / E u} \leq s}\left(y_{\text {iprediction }}^{\mathrm{Ba} / \mathrm{Eu}}-c_{1}\right)^{2}+\min \left(\sum_{x_{i}^{B a / E u}>s}\left(y_{i \text { prediction }}^{\mathrm{Ba} / \mathrm{Eu}}-c_{2}\right)^{2}\right)\right\} ; \\
& c_{1}=\frac{1}{N} \sum_{x_{i}^{\mathrm{Ba} / \mathrm{Eu}_{\leq s}}} y_{i}^{\mathrm{Ba} / \mathrm{Eu}}, c_{2}=\frac{1}{M} \sum_{x_{i}^{\mathrm{Ba} / \mathrm{Eu}_{>s}}} y_{i}^{\mathrm{Ba} / \mathrm{Eu}},
\end{aligned}
$$

where $N$ and $M$ are the feature value numbers in the different parts.

Based on the binary split process described above, for every feature $\left(x_{1}^{\mathrm{Ba}} / x_{1}^{\mathrm{Eu}}\right), \ldots,\left(x_{i}^{\mathrm{Ba}} / x_{i}^{\mathrm{Eu}}\right)$, if the feature value $y_{1 \text { prediction }}^{\mathrm{Ba} / \mathrm{Eu}} y_{\text {iprediction }}^{\mathrm{Ba} / \mathrm{Eu}}$ is greater than the best split value, we traverse the left side of the regression tree, i.e., the left subtree Tree left. If the feature value is lower than the best split value,

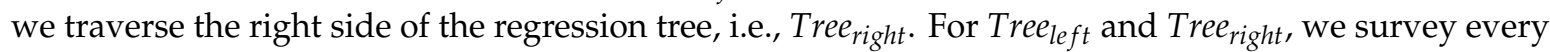
feature and feature value to find the best split until the minimum error is achieved (cf. Equation (5)). The binary split process is recursive for many iterations until the feature cannot be split; then, its feature value is the leaf node. Hence, the Ba interference with the Eu regression trees can be determined.

\subsection{Model Tree}

The model tree for prediction of $\mathrm{Ba}$ interference with $\mathrm{Eu}$ is based on the linear regression and regression tree models described above. The steps of the CART algorithm for this model tree are similar to those for the regression tree.

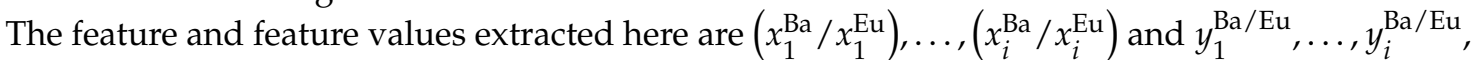
respectively. For every $\left(x_{1}^{\mathrm{Ba}} / x_{1}^{\mathrm{Eu}}\right), \ldots,\left(x_{i}^{\mathrm{Ba}} / x_{i}^{\mathrm{Eu}}\right)$, we execute binary splits that yield two parts $\left(x_{1}^{\mathrm{Ba}} / x_{1}^{\mathrm{Eu}}\right), \ldots,\left(x_{j}^{\mathrm{Ba}} / x_{j}^{\mathrm{Eu}}\right)<s,\left(x_{j}^{\mathrm{Ba}} / x_{j}^{\mathrm{Eu}}\right), \ldots,\left(x_{i}^{\mathrm{Ba}} / x_{i}^{\mathrm{Eu}}\right)>s$. Then, for every feature in the two different parts, we calculate $y_{1 \text { prediction }}^{\mathrm{Ba} / \mathrm{Eu}}, y_{\text {iprediction }}^{\mathrm{Ba} / \mathrm{Eu}}$ based on Equation (6). We repeat the process for every feature and every value to find the best split that minimizes the error; i.e.,:

$$
\begin{aligned}
& \min \left\{\min \sum_{x_{i}^{B a / E u} \leq s}\left(\left(x_{i}^{\mathrm{Ba}} / x_{i}^{\mathrm{Eu}}\right)^{T} w_{\text {iprediction }}-c_{1}\right)^{2}+\min \left(\sum_{x_{i}^{B a / E u}>s}\left(\left(x_{i}^{\mathrm{Ba}} / x_{i}^{\mathrm{Eu}}\right)^{T} w_{\text {iprediction }}-c_{2}\right)^{2}\right)\right\} \\
& c_{1}=\frac{1}{N} \sum_{x_{i}^{B a / E u} \leq s} y_{i}^{\mathrm{Ba} / \mathrm{Eu}} ; \quad c_{2}=\frac{1}{M} \sum_{x_{i}^{B a / E u}>s} y_{i}^{\mathrm{Ba} / \mathrm{Eu}} \\
& y_{\text {iprediction }}^{\mathrm{Ba} / \mathrm{Eu}}=\left(x_{i}^{\mathrm{Ba}} / x_{i}^{\mathrm{Eu}}\right)^{T} w_{i \text { prediction }} .
\end{aligned}
$$

Based on the binary split process above, for every feature $\left(x_{1}^{\mathrm{Ba}} / x_{1}^{\mathrm{Eu}}\right), \ldots,\left(x_{i}^{\mathrm{Ba}} / x_{i}^{\mathrm{Eu}}\right)$, if the feature value $\left\{\left(x_{1}^{\mathrm{Ba}} / x_{1}^{\mathrm{Eu}}\right)^{T} w_{1 \text { prediction }} \ldots,\left(x_{i}^{\mathrm{Ba}} / x_{i}^{\mathrm{Eu}}\right)^{T} w_{\text {iprediction }}\right\}$ is greater than the best split value, we traverse

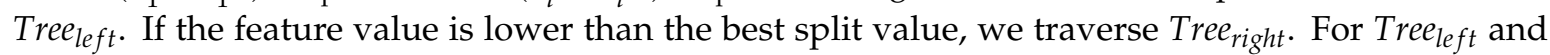
Tree $_{\text {right }}$, we survey every feature and feature value to find the best split until the minimum error is achieved (cf. Equation (6)). The binary split process is recursive for many iterations until the feature cannot be split; then, its feature value is the leaf node. Hence, model trees for Ba interference with Eu can be formed. The difference between the regression tree and model tree is that the leaf nodes of the

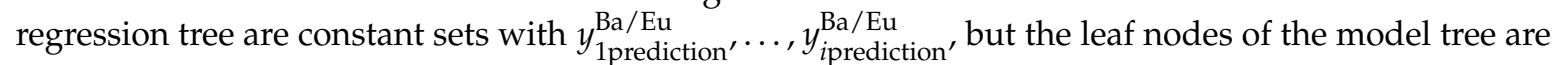
linear model sets with $\left\{\left(x_{1}^{\mathrm{Ba}} / x_{1}^{\mathrm{Eu}}\right)^{T} w_{1 \text { prediction }} \ldots,\left(x_{i}^{\mathrm{Ba}} / x_{i}^{\mathrm{Eu}}\right)^{T} w_{i \text { prediction }}\right\}$.

\subsection{Machine Learning Process for Ba-Eu Interference Prediction}

Based on the constructed regression tree and model tree for Ba-Eu interference prediction, the proposed machine learning process is implemented as follows.

Training: All $\left(x_{1}^{\mathrm{Ba}}, \ldots, x_{i}^{\mathrm{Ba}}\right),\left(x_{1}^{\mathrm{Eu}}, \ldots, x_{i}^{\mathrm{Eu}}\right),\left(x_{1}^{\mathrm{Ba}} / x_{1}^{\mathrm{Eu}}, \ldots, x_{i}^{\mathrm{Ba}} / x_{i}^{\mathrm{Eu}}\right)$, and $\left(y_{1}^{\mathrm{Ba} / \mathrm{Eu}}, \ldots, y_{i}^{\mathrm{Ba} / \mathrm{Eu}}\right)$ are entered. 
Regression tree for prediction: After regression tree training, we perform binary splits to obtain $P$ parts recursively, and obtain a prediction of the Ba-Eu interference $y_{i \text { prediction }}^{\mathrm{Ba} / \mathrm{Eu}}=\sum c_{p} I\left(x_{i}^{\mathrm{Ba} / \mathrm{Eu}} \in P\right)$ based on determination of the best split that minimizes the error:

$$
\begin{gathered}
\sum_{P} \min \left\{\min \sum_{x_{i}^{\mathrm{Ba} / \mathrm{Eu}} \leq s}\left(y_{i \text { prediction }}^{\mathrm{Ba} / \mathrm{Eu}}-c_{1}\right)^{2}+\min \left(\sum_{x_{i}^{\mathrm{Ba} / \mathrm{Eu}}>s}\left(y_{i \text { prediction }}^{\mathrm{Ba} / \mathrm{Eu}}-c_{2}\right)^{2}\right)\right\}, \\
c_{1}=\frac{1}{N} \sum_{x_{i}^{\mathrm{Ba} / \mathrm{Eu}} \leq s} y_{i}^{\mathrm{Ba} / \mathrm{Eu}}, c_{2}=\frac{1}{M} \sum_{x_{i}^{\mathrm{Ba} / \mathrm{Eu}}>s} y_{i}^{\mathrm{Ba} / \mathrm{Eu} .}
\end{gathered}
$$

Model tree for prediction: After the Ba-Eu interference model tree training, we execute binary splits to obtain $P$ parts recursively, and obtain $y_{i \text { prediction }}^{\mathrm{Ba} / \mathrm{Eu}}=\sum c_{p} I\left(x_{i}^{\mathrm{Ba} / \mathrm{Eu}} \in P\right)$ based on determination of the best split that minimizes the error:

$$
\begin{aligned}
& \sum_{p} \min \left\{\min \sum_{x_{i}^{\mathrm{Ba} / \mathrm{Eu}} \leq s}\left(\left(x_{i}^{\mathrm{Ba}} / x_{i}^{\mathrm{Eu}}\right)^{T} w_{i \text { prediction }}-c_{1}\right)^{2}+\min \left(\sum_{x_{i}^{\mathrm{B} / \mathrm{Eu}}>s}\left(\left(x_{i}^{\mathrm{Ba}} / x_{i}^{\mathrm{Eu}}\right)^{T} w_{i p r e d i c t i o n}-c_{2}\right)^{2}\right)\right\},
\end{aligned}
$$

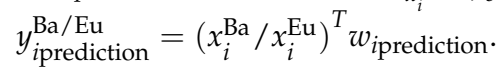

From the above analysis, the model tree for prediction of Ba interference with Eu is selected.

\section{Results and Performance Evaluation}

\subsection{Simulation Setup}

To implement the Ba-Eu interference prediction models and calculate the $\mathrm{Ba} / \mathrm{Eu}$ threshold value, the Python programming language [60] was used. The prediction models for the Ba interference with Eu were constructed as follows:

(1) All relevant element data were collected, as detailed in Tables 1 and 2.

(2) All input element data were prepared. Note that all $\mathrm{Ba}, \mathrm{Eu}$ and $\mathrm{Ba} / \mathrm{Eu}$ concentrations were prepared in a standard Python format list.

(3) The element data were analyzed. Note that all input element data could be analyzed for feature selection. These features included $x_{i}^{\mathrm{Ba}}, x_{i}^{\mathrm{Eu}}, x_{i}^{\mathrm{Ba}} / x_{i}^{\mathrm{Eu}}, y_{i}^{\mathrm{Ba} / \mathrm{Eu}}$, and $C_{i}^{\mathrm{Ba}}, C_{i}^{\mathrm{Eu}}$.

(4) The algorithm was trained. To achieve the target variable, i.e., the Ba interference with Eu, and the threshold points of the element, i.e., $\mathrm{Ba} / \mathrm{Eu}$, we implemented the model tree based on linear regression and the regression tree in Python.

(5) The algorithm was tested. That is, the performance of the interference prediction model obtained in the above step was tested.

Table 1. Description for $\mathrm{Ba} / \mathrm{Eu}$ in related samples used by Yan et al. [27].

\begin{tabular}{cccc}
\hline Sample & Ba/Eu & Type & Description \\
\hline SRM2682b & 2247 & Coal & Bituminous Coal \\
SRM2685b & 292 & Fly ash & $\begin{array}{c}\text { National Institute of Standards and Technology } \\
\text { (NIST) standard reference samples }\end{array}$ \\
SRM2690 & 2900 & Low-rank Coal & $\begin{array}{c}\text { No. } 6 \text { coal of Wulantuga Deposit (Shengli } \\
\text { Coalfield, Inner Mongolia [61]) }\end{array}$ \\
WLTG C6-2 & 18,598 & No. 4 coal of Zhoujing Mine, Baise Coalfield, \\
Guangxi Province
\end{tabular}


Table 2. Certified (Cer), Before separation (BS) and after separation (Steps 1-4) values of Eu and Ba ( $\mu$ g/g) in coal and coal-related samples [27] (BDL: below detection limit).

\begin{tabular}{|c|c|c|c|c|c|c|c|c|c|c|c|c|c|c|c|c|}
\hline \multirow{2}{*}{ Elements } & \multicolumn{6}{|c|}{ SRM2690 $(\mathrm{Ba} / \mathrm{Eu}=2900)$} & \multicolumn{5}{|c|}{$\mathrm{X} 1-1 \mathrm{R}(\mathrm{Ba} / \mathrm{Eu}=202,200)$} & \multicolumn{5}{|c|}{$\mathrm{X} 1-2 \mathrm{R}(\mathrm{Ba} / \mathrm{Eu}=42,236)$} \\
\hline & Cer & BS & Step 1 & Step 2 & Step 3 & Step 4 & BS & Step 1 & Step 2 & Step 3 & Step 4 & BS & Step 1 & Step 2 & Step 3 & Step 4 \\
\hline${ }^{153} \mathrm{Eu}$ & 2.00 & 4.01 & BDL & 0.00 & 1.87 & 2.00 & 0.52 & BDL & 0.00 & 0.62 & 0.01 & 0.25 & BDL & BDL & 0.25 & 0.02 \\
\hline${ }^{137} \mathrm{Ba}$ & 5800.00 & 6390 & 1.06 & 0.34 & 5852.23 & 112.10 & 1895.23 & 0.45 & 0.07 & 2022.00 & 22.03 & 814.53 & 4.02 & 0.09 & 844.67 & 12.66 \\
\hline \multirow{2}{*}{ Elements } & \multicolumn{6}{|c|}{ SRM2691 $(\mathrm{Ba} / \mathrm{Eu}=2950)$} & \multicolumn{5}{|c|}{$\mathrm{Z2-15F}(\mathrm{Ba} / \mathrm{Eu}=51,027)$} & \multicolumn{5}{|c|}{$\mathrm{Z2-16F}(\mathrm{Ba} / \mathrm{Eu}=33,816)$} \\
\hline & Cer & BS & Step 1 & Step 2 & Step 3 & Step 4 & BS & Step 1 & Step 2 & Step 3 & Step 4 & BS & Step 1 & Step 2 & Step 3 & Step 4 \\
\hline${ }^{153} \mathrm{Eu}$ & 2.00 & 4.08 & BDL & BDL & 1.88 & 1.93 & 0.44 & BDL & BDL & 0.45 & 0.03 & 0.38 & BDL & BDL & 0.42 & 0.05 \\
\hline${ }^{137} \mathrm{Ba}$ & 5900.00 & 6109.00 & 0.88 & 0.52 & 6392.00 & 193.00 & 1493.23 & 0.79 & 0.03 & 1530.89 & 32.79 & 1357.23 & 2.85 & 0.26 & 1690.89 & 22.93 \\
\hline \multirow{2}{*}{ Elements } & \multicolumn{6}{|c|}{ SRM2682b $(\mathrm{Ba} / \mathrm{Eu}=2247)$} & \multicolumn{5}{|c|}{$\mathrm{ZJ}-4-6$ (Ba/Eu = 3813) } & \multicolumn{5}{|c|}{$\mathrm{ZJ}-5-12(\mathrm{Ba} / \mathrm{Eu}=2083)$} \\
\hline & Cer & BS & Step 1 & Step 2 & Step 3 & Step 4 & BS & Step 1 & Step 2 & Step 3 & Step 4 & BS & Step 1 & Step 2 & Step 3 & Step 4 \\
\hline${ }^{153} \mathrm{Eu}$ & 0.17 & 0.23 & $\mathrm{BDL}$ & $\mathrm{BDL}$ & 0.07 & 0.16 & 0.18 & BDL & 0.00 & 0.08 & 0.10 & 0.24 & BDL & BDL & 0.08 & 0.17 \\
\hline${ }^{137} \mathrm{Ba}$ & 382.00 & 368.77 & $\mathrm{BDL}$ & 0.54 & 407.21 & 0.83 & 350.47 & $\mathrm{BDL}$ & 0.42 & 381.32 & $\mathrm{BDL}$ & 329.47 & 1.80 & 0.60 & 353.99 & BDL \\
\hline \multirow{2}{*}{ Elements } & \multicolumn{6}{|c|}{ SRM2685b $(\mathrm{Ba} / \mathrm{Eu}=292)$} & \multicolumn{5}{|c|}{ WTGC6-2 (Ba/Eu = 18,598) } & \multicolumn{5}{|c|}{ LL5-K3-8 (Ba/Eu = 13.18) } \\
\hline & Cer & BS & Step 1 & Step 2 & Step 3 & Step 4 & BS & Step 1 & Step 2 & Step 3 & Step 4 & BS & Step 1 & Step 2 & Step 3 & Step 4 \\
\hline${ }^{153} \mathrm{Eu}$ & 0.36 & 0.33 & BDL & BDL & 0.02 & 0.34 & 0.61 & BDL & BDL & 0.54 & 0.14 & 2.59 & BDL & BDL & 0.03 & 2.41 \\
\hline${ }^{137} \mathrm{Ba}$ & 105.00 & 97.60 & BDL & 0.40 & 113.10 & BDL & 2428.27 & 0.40 & 0.40 & 2603.77 & BDL & 26.23 & 3.43 & 0.68 & 31.77 & 3.72 \\
\hline \multirow{2}{*}{ Elements } & & LL5-K3 & 13(Ba/Eu & $=10.69)$ & & & & & & & & & & & & \\
\hline & BS & Step 1 & Step 2 & Step 3 & Step 4 & & & & & & & & & & & \\
\hline${ }^{153} \mathrm{Eu}$ & 2.23 & BDL & 0.01 & BDL & 2.24 & & & & & & & & & & & \\
\hline${ }^{137} \mathrm{Ba}$ & 19.00 & BDL & BDL & 23.94 & 2.15 & & & & & & & & & & & \\
\hline
\end{tabular}




\subsection{Model Tree for Prediction of Ba Interference with Eu}

The input element data sets were prepared as detailed in Table 3. For execution of the model tree for element interference prediction in Python, two variables were necessary: tolS and tolN, the tolerance of the Ba-Eu interference error reduction and the minimum Ba related to Eu data instances in a split, respectively. Note that the model tree was sensitive to the tolS and tolN settings. and different settings yielded different prediction models.

Table 3. Training data [27].

\begin{tabular}{cccc}
\hline Sample & Group No & $\mathbf{B a} / \mathbf{E u}$ & Ba Interference with Eu \\
\hline SRM2682b & 1 & 8.48 & 0.01 \\
SRM2685b & 2 & 10.88 & 0.03 \\
SRM2690 & 3 & 291.67 & 0.02 \\
SRM2691 & 4 & 1938.06 & 0.08 \\
WLTGC6-2 & 5 & 2247.06 & 0.07 \\
ZJ-4-6 & 6 & 2900 & 1.87 \\
ZJ-5-12 & 7 & 2950 & 1.88 \\
X1-1R & 8 & 3504.7 & 0.08 \\
X1-2R & 9 & $17,344.79$ & 0.54 \\
Z2-15F & 10 & $27,144.6$ & 0.42 \\
Z2-16F & 11 & $40,726.5$ & 0.25 \\
LL5-K3-8 & 12 & $49,774.33$ & 0.45 \\
LL5-K3-13 & 13 & 189,523 & 0.62 \\
\hline
\end{tabular}

We performed model tree experiments for element interference prediction by inputting rare earth element data sets. All prediction models are detailed in Table 4. For $($ tols, tolN $)=(0,1)$ and $(0,2)$, the prediction model for Ba interference with $\mathrm{Eu}$ is shown in Figure 2a. There are six split values: (1) when the Ba/Eu value is greater than 40,726.5, the Ba-Eu interference prediction model is a linear regression, where $y=0.389451044+0.00000121646954 \times x, x>40,726.5$; (2) when the $\mathrm{Ba} / \mathrm{Eu}$ value is less than $40,726.5$ and greater than $17,344.79$, the interference prediction model is a linear regression, with $y=0.759759680-0.0000125166582 \times x, 17,344.79<x<40,726.5$; (3) when the Ba/Eu value is less than 17,344.79 and greater than 2950, the interference prediction model is a linear regression, where $y=-0.0364849362+0.0000332367781 \times x, 2950<x<17,344.79$; (4) when the $\mathrm{Ba} / \mathrm{Eu}$ value is less than 2950 and greater than 2247.06, the interference prediction model is a linear regression, with $y=1.29+0.0002 \times x, 2247.06<x<2950$; (5) when the $\mathrm{Ba} / \mathrm{Eu}$ value is less than 2247.06 and greater than 10.88, the interference prediction model is a linear regression, with $y=0.0131201121+$ $0.0000291815483 \times x, 10.88<x<2247.06$; and (6) when the $\mathrm{Ba} / \mathrm{Eu}$ value is less than 10.88 , the interference prediction model is a linear regression, where $y=-0.06066667+0.00833333 \times x, x<10.88$.

Table 4. Prediction models for Ba interference with Eu based on model tree.

\begin{tabular}{|c|c|}
\hline Variables (tols, tolN) & $\begin{array}{l}\text { Prediction Models for Ba Interference with Eu Based on } \\
\text { Model Tree }\end{array}$ \\
\hline$(0,1),(0,2)$ & $\begin{array}{c}y=0.389451044+0.00000121646954 \times x, x>40,726.5 ; \\
y=0.759759680-0.0000125166582 \times x, 17,344.79<x<40,726.5 ; \\
y=-0.0364849362+0.0000332367781 \times x, 2950<x<17,344.79 ; \\
y=1.29+0.0002 \times x, 2247.06<x<2950 ; \\
y=0.0131201121+0.0000291815483 \times x, 10.88<x<2247.06 ; \\
y=-0.06066667+0.00833333 \times x, x<10.88\end{array}$ \\
\hline$(0,3)$ & $\begin{array}{c}y=0.259761293+0.00000193096467 \times x, x>27,144.6 \\
y=0.0966488103+0.0000156280402 \times x, 2950.0<x<27,144.6 \\
y=-5.88574265+0.00265247237 \times x, 1938.06<x<2950.0 \\
y=0.0169820389+0.0000320448913 \times x, x<1938.06\end{array}$ \\
\hline$(0,4),(0,5),(0,6),(1,4),(1,5),(1,6),(2,4),(2,5),(2,6)$ & $\begin{array}{c}y=-0.18419411+0.00050737 \times x, 0<x<2950 \\
y=0.293982186+0.00000181729975 \times x, 2950<x<189,523\end{array}$ \\
\hline$(0,7, \ldots, \infty),(1,7, \ldots, \infty),(2,7, \ldots, \infty),(3, \ldots, \infty, 1, \ldots, \infty)$ & $y=0.471722528+5.54453477 \times 10^{-7} \times x$ \\
\hline$(1,1),(1,2),(2,1),(2,2)$ & $\begin{array}{c}y=0.293982186+0.00000181729975 \times x, x>2950 \\
y=1.29+0.0002 \times x, 2247.06<x<2950 \\
y=0.017931963+0.0000267651624 \times x, x<2247.06\end{array}$ \\
\hline$(1,3)(2,3)$ & $\begin{array}{c}y=0.293982186+0.00000181729975 \times x, x>2950 \\
y=-5.88574265+0.00265247237 \times x, 1938.06<x<2950 \\
y=0.0169820389+0.0000320448913 \times x, x<1938.06\end{array}$ \\
\hline
\end{tabular}


A

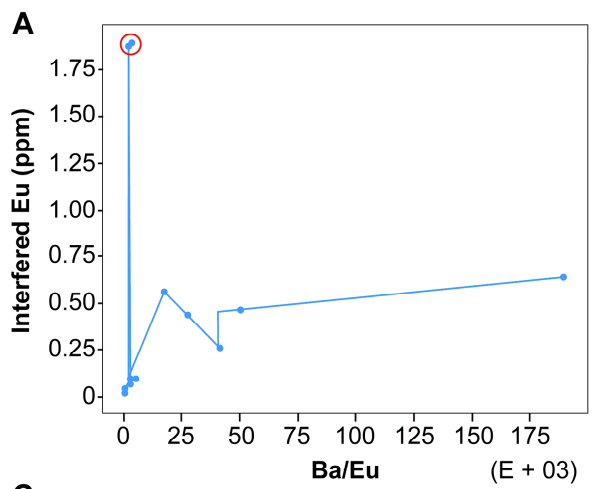

C
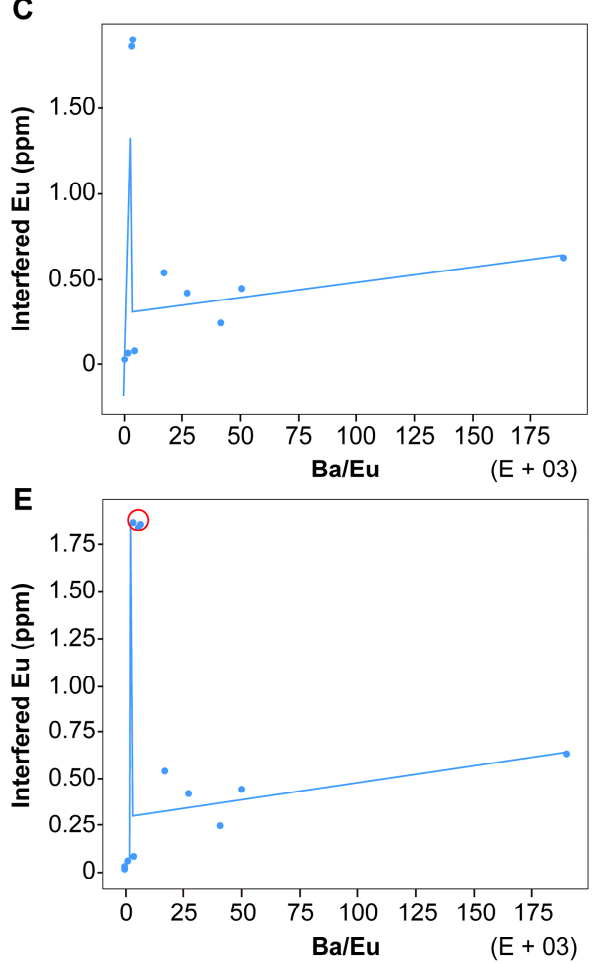

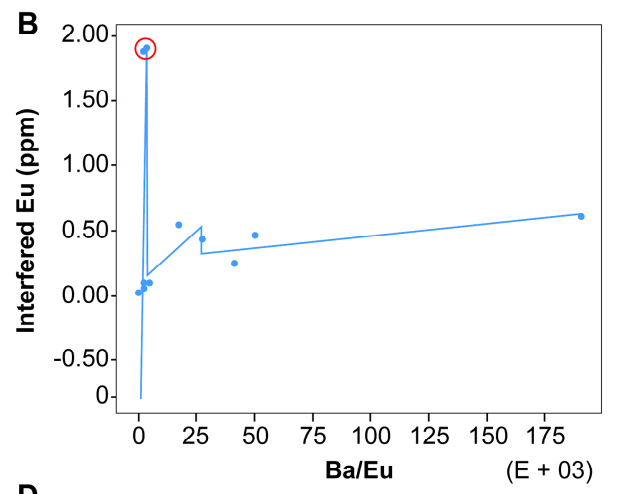

D
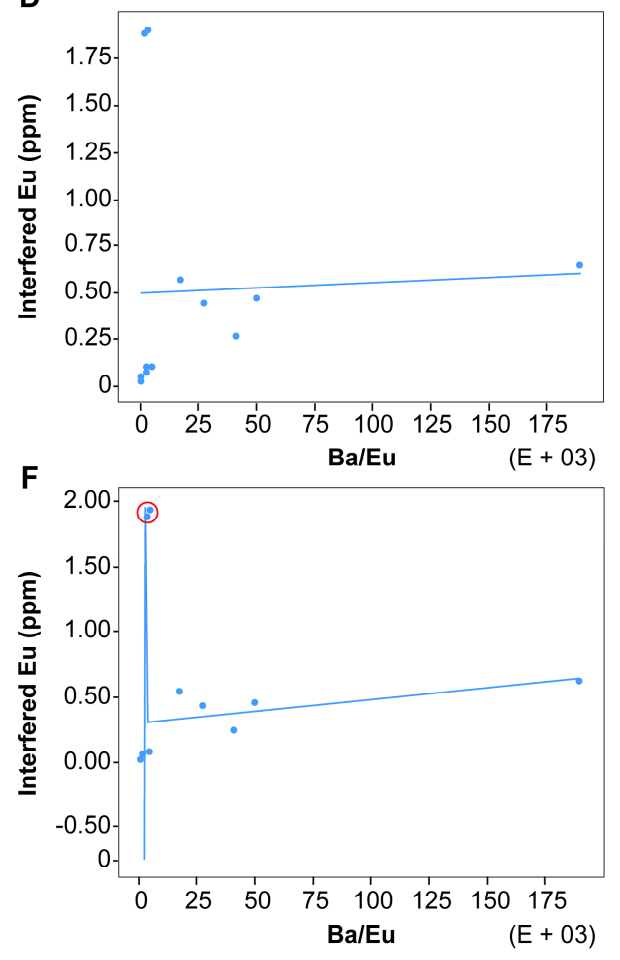

Figure 2. Prediction models with variables $($ tols, tolN) of $(\mathbf{a})(0,1),(0,2) ;(\mathbf{b})(0,3) ;(\mathbf{c})(0,4),(0,5),(0,6)$, $(1,4),(1,5),(1,6),(2,4),(2,5),(2,6) ;(\mathbf{d})(0,7, \ldots, \infty),(1,7, \ldots, \infty),(2,7, \ldots, \infty),(3, \ldots, \infty, 1, \ldots, \infty) ;(\mathbf{e})(1,1)$, $(1,2),(2,1),(2,2) ;(\mathbf{f})(1,3)(2,3)$.

For $(t o l s, t o l N)=(0,3)$, the model trees for prediction of Ba interference with Eu are shown in Figure 2b, having four split values: (1) when the $\mathrm{Ba} / \mathrm{Eu}$ value is greater than $27,144.6$, the interference prediction model is a linear regression, with $y=0.259761293+0.00000193096467 \times x, x>27,144.6$; (2) when the $\mathrm{Ba} / \mathrm{Eu}$ value is greater than 2950 and less than $27,144.6$, the interference prediction model is a linear regression, with $y=0.0966488103+0.0000156280402 \times x, 2950.0<x<27,144.6$; (3) when the $\mathrm{Ba} / \mathrm{Eu}$ value is less than 2950 and greater than 1938.06, the interference prediction model is a linear regression, where $y=-5.88574265+0.00265247237 \times x, 1938.06<x<2950.0$; and (4) when the $\mathrm{Ba} / \mathrm{Eu}$ value is less than 1938.06 , the interference prediction model is a linear regression, where $y=0.0169820389+0.0000320448913 \times x, x<1938.06$.

For $($ tols, tolN $)=(0,4),(0,5),(0,6),(1,4),(1,5),(1,6),(2,4),(2,5),(2,6)$, the model trees for interference prediction of $\mathrm{Ba}$ on $\mathrm{Eu}$ are shown in Figure 2c. (1) When the $\mathrm{Ba} / \mathrm{Eu}$ value is less than 2950, the Ba interference with Eu prediction model is a linear regression, with $y=-0.18419411+0.00050737 \times x, 0<$ $x<2950$; (2) when the $\mathrm{Ba} / \mathrm{Eu}$ value is greater than 2950 and less than 189,523, the interference prediction model is a linear regression, where $y=0.293982186+0.00000181729975 \times x, 2950<x<189,523$. 
For $($ tols, tolN $)=(0,7, \ldots, \infty),(1,7, \ldots, \infty),(2,7, \ldots, \infty),(3, \ldots, \infty, 1, \ldots, \infty)$, the model trees for prediction of Ba interference with Eu are shown in Figure 2d.

For $($ tols, tolN $)=(1,1),(1,2),(2,1)$, and $(2,2)$, the model trees for prediction of Ba interference with $\mathrm{Eu}$ are shown in Figure 2e. (1) When the Ba/Eu value is greater than 2950, the interference prediction model is a linear regression, with $y=0.293982186+0.00000181729975 \times x, x>2950$; (2) when the $\mathrm{Ba} / \mathrm{Eu}$ value is less than 2950 and greater than 2247.06, the interference prediction model is a linear regression, where $y=1.29+0.0002 \times x, 2247.06<x<2950$; and (3) when the $\mathrm{Ba} / \mathrm{Eu}$ value is less than 2247.06 , the interference prediction model is a linear regression, with $y=$ $0.017931963+0.0000267651624 \times x, x<2247.06$.

For $(t o l S$, tolN $)=(1,3),(2,3)$, the model trees for prediction of Ba interference with Eu are shown in Figure 2f. (1) When the $\mathrm{Ba} / \mathrm{Eu}$ value is greater than 2950, the interference prediction model is a linear regression, with $y=0.293982186+0.00000181729975 \times x, x>2950$; (2) when the Ba/Eu value is less than 2950 and greater than 1938.06, the interference prediction model is a linear regression, where $y=-5.88574265+0.00265247237 \times x, 1938.06<x<2950$; and (3) when the $\mathrm{Ba} / \mathrm{Eu}$ value is less than 1938.06, the interference prediction model is a linear regression, with $y=0.0169820389+$ $0.0000320448913 \times x, x<1938.06$.

\subsection{Results}

For all the model trees of the Ba-Eu interference prediction model illustrated in Figure 2, the training data sets of the $\mathrm{Ba} / \mathrm{Eu}$ ratio and the Ba interference with Eu were scattered, as shown in Figure 1. The points $(2900,1.87)$ and $(2950,1.88)$ were outliers from the other Ba/Eu ratio and Ba interference with Eu data points.

All prediction models with $($ tols, tolN $)=(0,1),(0,2),(0,3),(1,1),(1,2),(2,1),(2,2),(1,3)$, and $(2,3)$ contained outlier points of $(2950,1.88)$ and $(2900,1.87)$. The prediction models with $($ tols, tolN $)=$ $(0,7, \ldots, \infty),(1,7, \ldots, \infty),(2,7, \ldots, \infty),(3, \ldots, \infty, 1, \ldots, \infty)$ yielded lower prediction accuracy; thus, these models were imprecise.

The optimal values of (tols, tolN) for the prediction model of Ba interference with Eu were found to be $(0,4),(0,5),(0,6),(1,4),(1,5),(1,6),(2,4),(2,5)$, and $(2,6)$. When the Ba/Eu value was less than 2950, a linear regression was obtained for the interference prediction model, where $y=$ $-0.18419411+0.00050737 \times x, 0<x<2950$. Further, when the Ba/Eu value was greater than 2950 and less than 189,523, the interference prediction model was found to be a linear regression, with $y=0.293982186+0.00000181729975 \times x, 2950<x<189,523$. From the optimal models, a threshold point value of 363.0370538 could be determined. Note that, when the $\mathrm{Ba} / \mathrm{Eu}$ value is 363.0370538, it is not necessary to consider the Ba interference with Eu; thus, the Eu values can be interpreted from the data for the investigated samples.

\subsection{Performance Evaluation}

To verify the threshold value for Ba interference with Eu proposed in this paper, a wide dataset of Ba/Eu values covering 2-361 through 379-938 to 1042-3305 from previously published literature was used (Tables 5 and 6) [62,64,65]. The data for the testing were selected from Dai et al. [62,64] and Duan et al. [65], because these data points were all obtained via ICP-Q-MS. Thus, the Ba concentrations were expected to interfere with the Eu concentrations in the samples if the Ba/Eu values exceeded the threshold value, either at 1000 (as proposed in previous works) or at 363 (as proposed in this study). A total of 41 coal bench samples from a boehmite-rich 36.37-m-thick Pennsylvanian coal seam in Inner Mongolia, northern China, were considered, which were reported by Dai et al. [64]. A total of 60 coal bench samples from three Ge-rich Neogene coals from Lincang, Yunnan Province, southwestern China, were considered, which were reported by Dai et al. [62]. Further, a total of 27 coal bench samples from Reshuihe, Zhenxiong, Yunnan Province, China, were considered, which were reported by Duan et al. [65]. The test datasets presented in Tables 5 and 6 could be classified into three groups: $\mathrm{Ba} / \mathrm{Eu}<363, \mathrm{Ba} / \mathrm{Eu}=363-1000$, and $\mathrm{Ba} / \mathrm{Eu}>1000$. We compared the threshold value of 
363 determined from our proposed model with the value of 1000 proposed by others (e.g., [4,27,35]). Based on Table 5, the correlation coefficient of Ba and Eu was 0.1326 and 0.9659 when Ba/Eu was $<363$ and $>1000$, respectively. When Ba/Eu varied from 363 to 1000, the Ba and Eu correlation coefficient remained as high as 0.9545 , as illustrated in Figure 3A. Based on Table 6, the correlation coefficient of $\mathrm{Ba}$ and Eu was 0.231 and 0.9318 when $\mathrm{Ba} / \mathrm{Eu}$ was $<363$ and $>1000$, respectively. When $\mathrm{Ba} / \mathrm{Eu}$ varied from 363 to 1000, the Ba and Eu correlation coefficient remained as high as 0.9317, as illustrated in Figure 3B. The distinctively different correlation coefficients for Ba and Eu in the different Ba/Eu ranges show that the threshold value of 363 is more accurate for determination of Ba interference with Eu than the previously proposed value of 1000 .
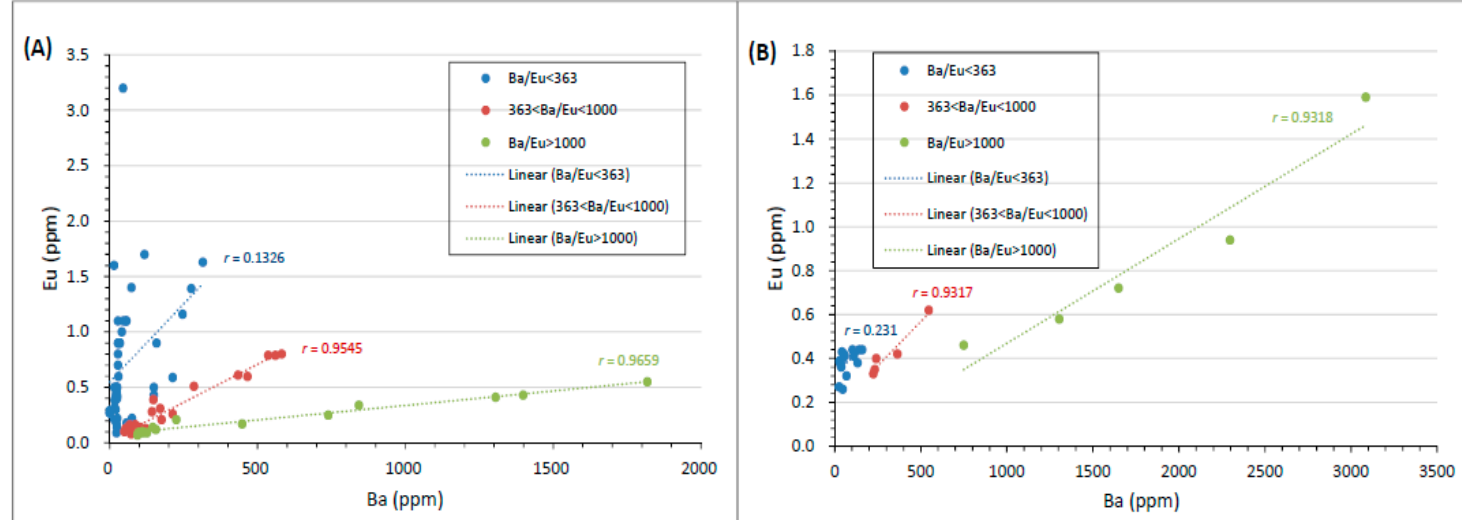

Figure 3. Performance comparison with test data of (A) Table 5; (B) Table 6.

Table 5. Ba, Eu, and Ba/Eu data for test (Data from Dai et al. $[62,64]$ ).

\begin{tabular}{cllc}
\hline Sample & Ba & Eu & Ba/Eu \\
\hline S3-1R & 434 & 0.61 & 711.4754098 \\
S3-2R & 315 & 1.63 & 193.2515337 \\
S3-4 & 81.3 & 0.12 & 677.5 \\
S3-5 & 87.3 & 0.14 & 623.5714286 \\
S3-6 & 85.9 & 0.16 & 536.875 \\
S3-7 & 93.0 & 0.10 & 930 \\
S3-8 & 113 & 0.09 & 1255.555556 \\
S3-9F & 213 & 0.59 & 361.0169492 \\
S3-10F & 536 & 0.79 & 678.4810127 \\
S3-11F & 561 & 0.79 & 710.1265823 \\
WA-S3 & 90.6 & 0.13 & 696.9230769 \\
Z2-1R & 466 & 0.60 & 776.6666667 \\
Z2-2 & 103 & 0.14 & 735.7142857 \\
Z2-3 & 111 & 0.10 & 1110 \\
Z2-4P & 448 & 0.17 & 2635.294118 \\
Z2-5P & 94.6 & 0.07 & 1351.428571 \\
Z2-5LP & 156 & 0.12 & 1300 \\
Z2-6P & 285 & 0.51 & 558.8235294 \\
Z2-7 & 101 & 0.09 & 1122.222222 \\
Z2-8 & 97.0 & 0.09 & 1077.777778 \\
Z2-9 & 79.4 & 0.11 & 721.8181818 \\
Z2-10 & 171 & 0.31 & 551.6129032 \\
Z2-11P & 213 & 0.26 & 819.2307692 \\
Z2-12 & 126 & 0.09 & 1400 \\
Z2-13 & 107 & 0.13 & 823.0769231 \\
Z2-14 & 226 & 0.21 & 1076.190476 \\
Z2-15F & 1398 & 0.43 & 3251.162791 \\
Z2-16F & 1305 & 0.41 & 3182.926829 \\
WA-Z2 & 122 & 0.13 & 938.4615385 \\
X1-1R & 1818 & 0.55 & 3305.454545 \\
X1-2R & 739 & 0.25 & 2956 \\
X1-3R & 843 & 0.34 & 2479.411765 \\
\hline & & &
\end{tabular}


Table 5. Cont.

\begin{tabular}{|c|c|c|c|}
\hline Sample & Ba & Eu & $\mathrm{Ba} / \mathrm{Eu}$ \\
\hline X1-4 & 84.2 & 0.13 & 647.6923077 \\
\hline$X 1-5$ & 77.7 & 0.12 & 647.5 \\
\hline$X 1-6$ & 86.1 & 0.12 & 717.5 \\
\hline X1-7 & 67.8 & 0.12 & 565 \\
\hline X1-8 & 99.3 & 0.11 & 902.7272727 \\
\hline X1-9 & 146 & 0.14 & 1042.857143 \\
\hline$X 1-10$ & 87.0 & 0.16 & 543.75 \\
\hline $\mathrm{X} 1-11$ & 82.5 & 0.14 & 589.2857143 \\
\hline $\mathrm{X} 1-12$ & 75.7 & 0.22 & 344.0909091 \\
\hline$X 1-13$ & 86.9 & 0.13 & 668.4615385 \\
\hline X1-14 & 70.6 & 0.10 & 706 \\
\hline X1-15 & 143 & 0.28 & 510.7142857 \\
\hline $\mathrm{X} 1-16 \mathrm{~F}$ & 276 & 1.39 & 198.5611511 \\
\hline $\mathrm{X} 1-17 \mathrm{~F}$ & 247 & 1.16 & 212.9310345 \\
\hline $\mathrm{X} 1-18 \mathrm{~F}$ & 582 & 0.80 & 727.5 \\
\hline WA-X1 & 91 & 0.14 & 650 \\
\hline $1418-1$ & 58 & 0.18 & 322.2222222 \\
\hline $1418-2$ & 54 & 0.13 & 415.3846154 \\
\hline $1418-3$ & 148 & 0.39 & 379.4871795 \\
\hline $\mathrm{H}-15$ & 25 & 0.5 & 50 \\
\hline $\mathrm{H}-16$ & 28 & 0.8 & 35 \\
\hline $\mathrm{H}-17$ & 24 & 0.46 & 52.17391304 \\
\hline $\mathrm{H}-18$ & 16 & 0.21 & 76.19047619 \\
\hline $\mathrm{H}-19$ & 23 & 0.42 & 54.76190476 \\
\hline $\mathrm{H}-20$ & 26 & 0.22 & 118.1818182 \\
\hline $\mathrm{H}-21$ & 18 & 0.39 & 46.15384615 \\
\hline H-22 & 21 & 0.39 & 53.84615385 \\
\hline H-22-23-P & 25 & 0.14 & 178.5714286 \\
\hline H-23 & 18 & 0.38 & 47.36842105 \\
\hline H-24 & 20 & 0.30 & 66.666666667 \\
\hline H-24-25-P & 24 & 0.17 & 141.1764706 \\
\hline H-25 & 34 & 0.9 & 37.77777778 \\
\hline $\mathrm{H}-26$ & 16 & 0.5 & 32 \\
\hline $\mathrm{H}-27$ & 24 & 0.49 & 48.97959184 \\
\hline $\mathrm{H}-28$ & 30 & 0.9 & 33.33333333 \\
\hline $\mathrm{H}-29$ & 28 & 0.9 & 31.11111111 \\
\hline H-B1 & 17 & 0.32 & 53.125 \\
\hline H-B2 & 28 & 1.1 & 25.45454545 \\
\hline H-B3 & 118 & 1.7 & 69.41176471 \\
\hline WG-1 & 176 & 0.21 & 838.0952381 \\
\hline CS-1 & 68 & 0.16 & 425 \\
\hline $1104 / 1$ & 50.6 & 0.1 & 506 \\
\hline $\mathrm{H}-\mathrm{T}$ & 1029 & 1.0 & 1029 \\
\hline H-1 & 25 & 0.5 & 50 \\
\hline H-1-2-P & 45 & 3.2 & 14.0625 \\
\hline H-4 & 74 & 1.4 & 52.85714286 \\
\hline H-5 & 32 & 0.9 & 35.55555556 \\
\hline H-5-6-P1 & 57 & 1.1 & 51.81818182 \\
\hline H-5-6-P2 & 25 & 0.4 & 62.5 \\
\hline H-6 & 35 & 0.9 & 38.88888889 \\
\hline H-7 & 46 & 1.1 & 41.81818182 \\
\hline H-8 & 30 & 0.6 & 50 \\
\hline H-8-9-P & 23 & 0.09 & 255.5555556 \\
\hline H-9 & 15 & 1.6 & 9.375 \\
\hline $\mathrm{H}-10$ & 28 & 0.7 & 40 \\
\hline $\mathrm{H}-11$ & 22 & 0.44 & 50 \\
\hline $\mathrm{H}-12$ & 26 & 0.42 & 61.9047619 \\
\hline $\mathrm{H}-13$ & 21 & 0.41 & 51.2195122 \\
\hline H-14 & 22 & 0.5 & 44 \\
\hline S3-4 & 81.3 & 0.12 & 677.5 \\
\hline $1418-4$ & 73 & 0.08 & 912.5 \\
\hline
\end{tabular}


Table 6. Ba, Eu, and Ba/Eu data for test (Data from Duan et al. [65]).

\begin{tabular}{cllc}
\hline Sample & Ba & Eu & Ba/Eu \\
\hline 1 & 41.37 & 0.43 & 96.2093023 \\
2 & 37.07 & 0.36 & 102.972222 \\
3 & 57.96 & 0.41 & 141.365854 \\
4 & 102.69 & 0.44 & 233.386364 \\
5 & 142.94 & 0.44 & 324.863636 \\
6 & 223.67 & 0.33 & 678 \\
7 & 34.81 & 0.38 & 91.6052632 \\
8 & 30.59 & 0.38 & 80.5 \\
9 & 33.97 & 0.37 & 91.8108108 \\
10 & 52.04 & 0.42 & 123.904762 \\
11 & 110.63 & 0.41 & 269.829268 \\
12 & 158.85 & 0.44 & 361.022727 \\
13 & 240.5 & 0.4 & 601 \\
14 & 32.9 & 0.39 & 84.3589744 \\
15 & 45.71 & 0.26 & 175.807692 \\
16 & 67.95 & 0.32 & 212.34375 \\
17 & 132.77 & 0.38 & 349.394737 \\
18 & 231.42 & 0.35 & 661 \\
19 & 364.43 & 0.42 & 868 \\
20 & 546.4 & 0.62 & 881 \\
21 & 25.16 & 0.27 & 93.1851852 \\
22 & 28.98 & 0.39 & 74.3076923 \\
23 & 749.07 & 0.46 & 1628.41304 \\
24 & 1304.88 & 0.58 & 2249.7931 \\
25 & 1648.57 & 0.72 & 2289.68056 \\
26 & 2296.27 & 0.94 & 2442.84043 \\
27 & 3086.02 & 1.59 & 1940.89308 \\
28 & 28.98 & 0.39 & 74.30769231 \\
\hline
\end{tabular}

1-7, Size (mm): 6-13, Density (kg/L): <1.4, 1.4-1.5, 1.5-1.6, 1.6-1.7, 1.7-1.8, >1.8, Feed coal; 8-14, Size (mm): 3-6 mm, Density (kg/L): $<1.4,1.4-1.5,1.5-1.6,1.6-1.7,1.7-1.8,>1.8$, Feed coal; $15-21$, Size (mm): 0.5-3 mm; Density (kg/L): $<1.4,1.4-1.5,1.5-1.6,1.6-1.7,1.7-1.8,>1.8$, Feed coal; 22-28, Size (mm): $<0.5 \mathrm{~mm}$, Density (kg/L): $<1.4,1.4-1.5$, $1.5-1.6,1.6-1.8,>1.8$, Feed coal.

\section{Conclusions}

In conclusion, to determine the threshold value of Ba interference with $\mathrm{Eu}$ in the context of ICP-Q-MS data analysis, three machine learning techniques-namely, the linear regression, regression tree, and model tree methods-were used to construct prediction models of Ba interference with Eu in coal and coal-related samples. The CART algorithm was applied to the tree regression. To apply the models for prediction of $\mathrm{Ba}$ interference with $\mathrm{Eu}$, all related data, including that on $\mathrm{Ba}, \mathrm{Eu}, \mathrm{Ba} / \mathrm{Eu}$, and Eu interference, were collected and prepared. A Ba-Eu interference linear regression model, regression tree, and model tree were implemented in Python for prediction. The results showed that the model tree is far superior to the regression tree for determination of $\mathrm{Ba} / \mathrm{Eu}$ threshold points. The extracted feature was $\mathrm{Ba} / \mathrm{Eu}$ and the extracted feature value was the interference of $\mathrm{Ba}$ with Eu. From all obtained prediction models, an optimal threshold point value of 363 was determined. This indicates that, when the $\mathrm{Ba} / \mathrm{Eu}$ value is $<363$, the Ba interference with Eu can be neglected; thus, the Eu concentrations in samples can be determined based on ICP-Q-MS data. Based on the results of simulations in which the threshold value of 363 proposed in this study and that of 1000 proposed in other works (e.g., $[4,27,35]$ ) were compared, the former is more accurate for determining whether Ba interferes with $\mathrm{Eu}$ in investigated samples. In the future, we will use deep learning techniques [66-68] to determine the threshold value of Ba interference with Eu.

Author Contributions: Conceptualization, N.X. and Q.L.; methodology, N.X. and Q.L.; validation, N.X. and Q.L.; formal analysis, N.X. and Q.L.; Writing-Original Draft preparation, N.X. 
Funding: This research was funded by the National Natural Science Foundation of China, grant number 61772320, and 111 Projects, grant number B17042.

Acknowledgments: We thank Xudong Mao of the City University of Hong Kong for help with the manuscript revision.

Conflicts of Interest: The authors declare no conflict of interest.

\section{References}

1. Barakos, G.; Mischo, H.; Gutzmer, J. An outlook on the rare earth elements mining industry. 2016. Available online: https://www.ausimmbulletin.com/feature/an-outlook-on-the-rare-earth-elements-mining-industry/ (accessed on 1 November 2018).

2. Hower, J.C.; Granite, E.J.; Mayfield, D.B.; Lewis, A.S.; Finkelman, R.B. Notes on contributions to the science of rare earth element enrichment in coal and coal combustion by-products. Minerals 2016, 6, 32. [CrossRef]

3. Seredin, V.V.; Dai, S. Coal deposits as potential alternative sources for lanthanides and yttrium. Int. J. Coal Geol. 2012, 94, 67-93. [CrossRef]

4. Dai, S.; Graham, I.T.; Ward, C.R. A review of anomalous rare earth elements and yttrium in coal. Int. J. Coal Geol. 2016, 159, 82-95. [CrossRef]

5. Dai, S.; Ward, C.R.; Graham, I.T.; French, D.; Hower, J.C.; Zhao, L.; Wang, X. Altered volcanic ashes in coal and coal-bearing sequences: A review of their nature and significance. Earth Sci. Rev. 2017, 175, 44-74. [CrossRef]

6. Dai, S.; Yan, X.; Ward, C.R.; Hower, J.C.; Zhao, L.; Wang, X.; Zhao, L.; Ren, D.; Finkelman, R.B. Valuable elements in Chinese coals: A review. Int. Geol. Rev. 2018, 60, 590-620.

7. Dai, S.; Finkelman, R.B. Coal as a promising source of critical elements: Progress and future prospects. Int. J. Coal Geol. 2018, 186, 155-164. [CrossRef]

8. Seredin, V.V. REE-bearing coals from Russian Far East deposits. Int. J. Coal Geol. 1996, 30, 101-129. [CrossRef]

9. Hower, J.C.; Ruppert, L.F.; Eble, C.F. Lanthanide, yttrium, and zirconium anomalies in the fire clay coal bed, Eastern Kentucky. Int. J. Coal Geol. 1999, 39, 141-153. [CrossRef]

10. Hower, J.C.; Eble, C.F.; Dai, S.; Belkin, H.E. Distribution of rare earth elements in eastern Kentucky coals: Indicators of multiple modes of enrichment? Int. J. Coal Geol. 2016, 160-161, 73-81. [CrossRef]

11. Hower, J.C.; Dai, S. Petrology and chemistry of sized Pennsylvania anthracite, with emphasis on the distribution of rare earth elements. Fuel 2016, 185, 305-315. [CrossRef]

12. Lin, R.; Soong, Y.; Granite, E.J. Evaluation of trace elements in U.S. coals using the USGS COALQUAL database version 3.0. Part I: Rare earth elements and yttrium (REY). Int. J Coal Geol. 2018, 192, 1-13. [CrossRef]

13. Taggart, R.K.; Hower, J.C.; Dwyer, G.S.; Hsu-Kim, H. Trends in the rare earth element content of U.S.-based coal combustion fly ashes. Environ. Sci. Technol. 2016, 50, 5919-5926. [CrossRef]

14. Kolker, A.; Scott, C.; Hower, J.C.; Vazquez, J.A.; Lopano, C.L.; Dai, S. Distribution of rare earth elements in coal combustion fly ash, determined by SHRIMP-RG ion microprobe. Int. J. Coal Geol. 2017, 184, 1-10. [CrossRef]

15. Laudal, D.A.; Benson, S.A.; Addleman, R.S.; Palo, D. Leaching behavior of rare earth elements in Fort Union lignite coals of North America. Int. J Coal Geol. 2018, 191, 112-124. [CrossRef]

16. Zhang, W.; Honaker, R.Q. Rare earth elements recovery using staged precipitation from a leachate generated from coarse coal refuse. Int. J Coal Geol. 2018, 195, 189-199. [CrossRef]

17. Vito, I.E.D.; Olsina, R.A.; Masi, A.N. Enrichment method for trace amounts of rare earth elements using chemofiltration and XRF determination. Fresen. J. Anal. Chem. 2000, 368, 392-396. [CrossRef]

18. Smoliński, A.; Stempin, M.; Howaniec, N. Determination of rare earth elements in combustion ashes from selected Polish coal mines by wavelength dispersive X-ray fluorescence spectrometry. Spectrochim. Acta B 2016, 116, 63-74. [CrossRef]

19. Ohde, S. Determination of rare earth elements in carbonatites from the kangankunde mine, Malawi by instrumental neutron activation analysis. J. Radioanal. Nucl. Chem. 2003, 257, 433-435. [CrossRef]

20. Kumar, K.; Saion, E.; Halimah, M.K.; Yap, C.K.; Hamzah, M.S. Rare earth element (REE) in surface mangrove sediment by instrumental neutron activation analysis. J. Radioanal. Nucl. Chem. 2014, 301, 667-676. [CrossRef]

21. El-Taher, A. Rare earth elements content in geological samples from the Eastern Desert, Egypt, determined by instrumental neutron activation analysis. Appl. Radiat. Isot. 2010, 68, 1859-1863. [CrossRef] 
22. Cook, N.J.; Ciobanu, C.L.; O’Rielly, D.; Wilson, R.; Das, K.; Wade, B. Mineral chemistry of rare earth element (REE) mineralization, Browns Ranges, Western Australia. Lithos 2013, 172-173, 192-213. [CrossRef]

23. Thompson, R.L.; Bank, T.; Roth, E.; Granite, E. Resolution of rare earth element interferences in fossil energy by-product samples using sector-field ICP-MS. Fuel 2016, 185, 94-101. [CrossRef]

24. Gaft, M.; Dvir, E.; Modiano, H.; Schone, U. Laser induced breakdown spectroscopy machine for online ash analyses in coal. Spectrochim Acta B 2008, 63, 1177-1182. [CrossRef]

25. Stankova, A.; Gilon, N.; Dutruch, L.; Kanicky, V. A simple LIBS method for fast quantitative analysis of fly ashes. Fuel 2010, 89, 3468-3874. [CrossRef]

26. Haider, A.F.M.Y.; Rony, M.A.; Lubna, R.S.; Abedin, K.M. Detection of multiple elements in coal samples from Bangladesh by laser-induced breakdown spectroscopy. Opt. Laser Technol. 2011, 43, 1405-1410. [CrossRef]

27. Yan, X.; Dai, S.; Graham, I.T.; He, X.; Shan, K.; Liu, X. Determination of Eu concentrations in coal, fly ash and sedimentary rocks using a cation exchange resin and inductively coupled plasma mass spectrometry (ICP-MS). Int. J. Coal Geol. 2018, 191, 152-156. [CrossRef]

28. Zhang, Y.; Jiang, Z.; He, M.; Hu, B. Determination of trace rare earth elements in coal fly ash and atmospheric particulates by electrothermal vaporization inductively coupled plasma mass spectrometry with slurry sampling. Environ. Pollut. 2007, 148, 459-467. [CrossRef]

29. Ardini, F.; Soggia, F.; Rugi, F.; Udisti, R.; Grotti, M. Comparison of inductively coupled plasma spectrometry techniques for the direct determination of rare earth elements in digests from geological samples. Anal. Chim. Acta 2010, 678, 18-25. [CrossRef]

30. Gray, A.L.; Williams, J.G. Oxide and doubly charged ion response of a commercial inductively coupled plasma mass spectrometry instrument. J. Anal. At. Spectrom. 1987, 2, 51-82. [CrossRef]

31. Jarvis, K.E.; Gray, A.L.; McCurdy, E. Avoidance of spectral interference on europium in inductively coupled plasma mass spectrometry by sensitive measurement of the doubly charged ion. J. Anal. At. Spectrom. 1989, 4, 743-747. [CrossRef]

32. Raut, N.M.; Huang, L.S.; Aggarwal, S.K.; Lin, K.C. Determination of lanthanides in rock samples by inductively coupled plasma mass spectrometry using thorium as oxide and hydroxide correction standard. Spectrochim. Acta B 2003, 58, 809-822. [CrossRef]

33. Raut, N.M.; Huang, L.S.; Lin, K.C.; Aggarwal, S.K. Uncertainty propagation through correction methodology for the determination of rare earth elements by quadrupole based inductively coupled plasma mass spectrometry. Anal. Chim. Acta 2005, 530, 91-103. [CrossRef]

34. Zawisza, B.; Pytlakowska, K.; Feist, B.; Polowniak, M.; Kita, A.; Sitko, R. Determination of rare earth elements by spectroscopic techniques: A review. J. Anal. Atom. Spectrom. 2011, 26, 2373-2390. [CrossRef]

35. Loges, A.; Wagner, T.; Barth, M.; Bau, M.; Göb, S.; Markl, G. Negative Ce anomalies in Mn oxides: The role of $\mathrm{Ce}^{4+}$ mobility during water-mineral interaction. Geochim. Cosmochim. Acta. 2012, 86, 296-317. [CrossRef]

36. Ketris, M.P.; Yudovich, Y.E. Estimations of Clarkes for Carbonaceous biolithes: World average for trace element contents in black shales and coals. Int. J. Coal Geol. 2009, 78, 135-148. [CrossRef]

37. Palmer, C.A.; Oman, C.L.; Park, A.J.; Luppens, J.A. The U.S. Geological Survey Coal Quality (COALQUAL) Database Version 3.0. Data Series; The U.S. Geological Survey: Reston, VA, USA, 2015; p. 57.

38. Finkelman, R.B.; Palmer, C.A.; Wang, P. Quantification of the modes of occurrence of 42 elements in coal. Int. J. Coal Geol. 2018, 185, 138-160. [CrossRef]

39. Dai, S.F.; Ren, D.Y.; Chou, C.-L.; Li, S.S.; Jiang, Y.F. Mineralogy and geochemistry of the No. 6 Coal (Pennsylvanian) in the Junger Coalfield, Ordos Basin, China. Int. J. Coal Geol. 2006, 66, 253-270. [CrossRef]

40. Dai, S.F.; Wang, X.B.; Zhou, Y.P.; Hower, J.C.; Li, D.H.; Chen, W.M.; Zhu, X.W.; Zou, J.H. Chemical and mineralogical compositions of silicic, mafic, and alkali tonsteins in the Late Permian coals from the Songzao Coalfield, Chongqing, Southwest China. Chem. Geol. 2011, 282, 29-44. [CrossRef]

41. Liu, J.J.; Yang, Z.; Yan, X.Y.; Ji, D.; Yang, Y.P.; Hu, L.C. Modes of occurrence of highly-elevated trace elements in superhigh-organic-sulfur coals. Fuel 2015, 156, 190-197. [CrossRef]

42. Johnston, M.N.; Hower, J.C.; Dai, S.; Wang, P.; Xie, P.; Liu, J. Petrology and Geochemistry of the Harlan, Kellioka, and Darby Coals from the Louellen 7.5-Minute Quadrangle, Harlan County, Kentucky. Minerals 2015, 5, 894-918. [CrossRef]

43. Dai, S.; Ren, D.; Zhou, Y.; Chou, C.-L.; Wang, X.; Zhao, L.; Zhu, X. Mineralogy and geochemistry of a superhigh-organic-sulfur coal, Yanshan Coalfield, Yunnan, China: Evidence for a volcanic ash component and influence by submarine exhalation. Chem. Geol. 2008, 255, 182-194. [CrossRef] 
44. Dai, S.; Xie, P.; Jia, S.; Ward, C.R.; Hower, H.C.; Yan, X.; French, D. Enrichment of U-Re-V-Cr-Se and rare earth elements in the Late Permian coals of the Moxinpo Coalfield, Chongqing, China: Genetic implications from geochemical and mineralogical data. Ore Geol. Rev. 2017, 80, 1-17. [CrossRef]

45. Hower, J.C.; Eble, C.F.; O’Keefe, J.M.K.; Dai, S.; Wang, P.; Xie, P.; Liu, J.; Ward, C.R.; French, D. Petrology, Palynology, and Geochemistry of Gray Hawk Coal (Early Pennsylvanian, Langsettian) in Eastern Kentucky, USA. Minerals 2015, 5, 592-622. [CrossRef]

46. Liu, J.; Ward, C.R.; Graham, I.T.; French, D.; Dai, S.; Song, X. Modes of occurrence of non-mineral inorganic elements in lignites from the Mile Basin, Yunnan Province, China. Fuel 2018, 222, 146-155. [CrossRef]

47. Chang, C.; Fu, Q.; Wang, X. Linear Correlation of Ba and Eu Contents by Hydrothermal Activities: A Case Study in the Hetang Formation, South China. Geofluids 2019. [CrossRef]

48. Dulski, P. Interferences of oxide, hydroxide and chloride analyte species in the determination of rare earth elements in geological samples by inductively coupled plasma-mass spectrometry. Fresenius J. Anal. Chem. 1994, 350, 194-203. [CrossRef]

49. Smirnova, E.V.; Fedorova, I.N.; Sandimirova, G.P.; Petrov, L.L.; Balbekina, N.G.; Lozhkin, V.I. Determination of rare earth elements in black shales by inductively coupled plasma mass spectrometry. Spectrochim. Acta $B$ 2003, 58, 329-340. [CrossRef]

50. Wang, J.; Chen, D.; Wang, D.; Yan, D.; Zhou, X.; Wang, Q. Petrology and geochemistry of chert on the marginal zone of Yangtze platform, western Hunan, South China, during the Ediacaran-Cambrian transition. Sedimentology 2012, 59, 809-829. [CrossRef]

51. Jiang, S.Y.; Zhao, H.X.; Chen, Y.Q.; Yang, T.; Yang, J.H.; Ling, H.F. Trace and rare earth element geochemistry of phosphate nodules from the lower Cambrian black shale sequence in the Mufu Mountain of Nanjing, Jiangsu province, China. Chem. Geol. 2007, 244, 584-604. [CrossRef]

52. Shields, G.; Stille, P. Diagenetic constraints on the use of cerium anomalies as palaeoseawater redox proxies: An isotopic and REE study of Cambrian phosphorites. Chem. Geol. 2001, 175, 29-48. [CrossRef]

53. Dai, S.; Guo, W.; Nechaev, V.P.; French, D.; Ward, C.R.; Spiro, B.F.; Finkelman, R.B. Modes of occurrence and origin of mineral matter in the Palaeogene coal (No. 19-2) from the Hunchun Coalfield, Jilin Province, China. Int. J. Coal Geol. 2018, 189, 94-110. [CrossRef]

54. Dai, S.; Ji, D.; Ward, C.R.; French, D.; Hower, J.C.; Yan, X.; Wei, Q. Mississippian anthracites in Guangxi Province, southern China: Petrological, mineralogical, and rare earth element evidence for high-temperature solutions. Int. J. Coal Geol. 2018, 197, 84-114. [CrossRef]

55. Dai, S.; Xie, P.; Ward, C.R.; Yan, X.; Guo, W.; French, D.; Graham, I.T. Anomalies of rare metals in Lopingian super-high-organic-sulfur coals from the Yishan Coalfield, Guangxi, China. Ore Geol. Rev. 2017, 88, 235-250. [CrossRef]

56. Wang, Z.; Dai, S.; Zou, J.; French, D.; Graham, I.T. Rare earth elements and yttrium in coal ash from the Luzhou power plant in Sichuan, Southwest China: Concentration, characterization and optimized extraction. Int. J. Coal Geol. 2019, 203, 1-14. [CrossRef]

57. Harrington, P. Machine Learning in Action; Manning Publications: Shelter Island, NY, USA, 2012; p. 384.

58. Han, J.; Pei, J.; Kamber, M. Data Mining: Concepts and Techniques; Morgan Kaufmann: Burlington, MA, USA, 2011; p. 744.

59. Wu, X.; Kumar, V.; Ross Quinlan, J.; Ghosh, J.; Yang, Q.; Motoda, H.; McLachlan, G.J.; Ng, A.; Liu, B.; Yu, P.S.; et al. Top 10 algorithms in data mining. Knowl. Inf. Syst. 2008, 14, 1-37. [CrossRef]

60. McKinney, W. Python for Data Analysis; O'Reilly Media: Sebastopol, CA, USA, 2017; p. 511.

61. Dai, S.; Wang, X.; Seredin, V.V.; Hower, J.C.; Ward, C.R.; O’Keefe, J.M.K.; Huang, W.; Li, T.; Li, X.; Liu, H.; et al. Petrology, mineralogy, and geochemistry of the Ge-rich coal from the Wulantuga Ge ore deposit, Inner Mongolia, China: New data and genetic implications. Int. J. Coal Geol. 2012, 90-91, 72-99. [CrossRef]

62. Dai, S.; Wang, P.; Ward, C.R.; Tang, Y.; Song, X.; Jiang, J.; Hower, J.C.; Li, T.; Seredin, V.V.; Wagner, N.J.; et al. Elemental and mineralogical anomalies in the coal-hosted Ge ore deposit of Lincang, Yunnan, southwestern China: Key role of $\mathrm{N}_{2}-\mathrm{CO}_{2}$-mixed hydrothermal solutions. Int. J. Coal Geol. 2015, 152, 19-46. [CrossRef]

63. Wei, Q.; Rimmer, S.M.; Dai, S. Distribution of trace elements in fractions after micronization and density-gradient centrifugation of high-Ge coals from the Wulantuga and Lincang Ge ore deposits, China. Energy Fuels 2017, 31, 11818-11837. [CrossRef] 
64. Dai, S.; Li, D.; Chou, C.L.; Zhao, L.; Zhang, Y.; Ren, D.; Ma, Y.; Sun, Y. Mineralogy and geochemistry of boehmite-rich coals: New insights from the Haerwusu Surface Mine, Jungar Coalfield, Inner Mongolia, China. Int. J. Coal Geol. 2008, 74, 185-202. [CrossRef]

65. Duan, P.; Wang, W.; Liu, X.; Sang, S.; Ma, M.; Zhang, W. Differentiation of rare earth elements and yttrium in different size and density fractions of the Reshuihe coal, Yunnan Province, China. Int. J. Coal Geol. 2019, 207, 1-11. [CrossRef]

66. Li, L.; Ota, K.; Dong, M.; Borjigin, W. Eyes in the dark: Distributed scene understanding for disaster management. IEEE Trans. Parallel Distrib. Syst. 2017, 28, 3458-3471. [CrossRef]

67. Li, L.; Ota, K.; Dong, M. DeepNFV: A Light-weight Framework for Intelligent Edge Network Functions Virtualization. IEEE Network 2019, 33, 136-141. [CrossRef]

68. Ota, K.; Dao, M.S.; Mezaris, V.; De Natale, F.G. Deep Learning for Mobile Multimedia: A Survey. ACM Trans. Multimedia Comput. Commun. Appl. (TOMM) 2017, 13, 21. [CrossRef]

(C) 2019 by the authors. Licensee MDPI, Basel, Switzerland. This article is an open access article distributed under the terms and conditions of the Creative Commons Attribution (CC BY) license (http://creativecommons.org/licenses/by/4.0/). 